\title{
Synthesis and Characterisation of Zinc Layered Hydroxide Intercalated with 2-Methyl-4- Chlorophenoxyacetic Acid and its Controlled Release Application
}

\author{
Nur Syahidatul Insyirah Mohd Foad ${ }^{1}$, Nur Nadia Dzulkifli¹, Asiah Abdullah ${ }^{1}$, Monica Limau Jadam² and Sheikh Ahmad \\ Izaddin Sheikh Mohd Ghazali ${ }^{*}$ \\ ${ }^{1}$ Faculty of Applied Sciences,University Teknologi MARA, Negeri Sembilan branch, Kuala Pilah campus, 72000 Kuala Pilah, \\ Negeri Sembilan, Malaysia \\ ${ }^{2}$ Faculty of Applied Sciences, University Teknologi MARA, 40450 Shah Alam,Selangor, Malaysia
}

\begin{abstract}
2-methyl-4-chlorophenoxyacetic acid (MCPA) is herbicide in group of phenoxyherbicides. It has been widely used in agriculture industry to control the weeds population especially thistle and dock. The toxicity of MCPA may impact the environment and harmful for living organisms especially human and aquatic life. This research aimed to intercalate MCPA herbicide with zinc layered hydroxide (ZLH) to form a composites (ZMCPA) and its controlled release properties. In this study, ZMCPA was prepared as an advanced delivery system by ion exchange method and further by hydrothermal treatment. The intercalations of zinc oxide were done with various MCPA concentration of $0.1 \mathrm{M}, 0.3 \mathrm{M}$, 0.5 M, 0.7 M and 0.9 M. Intercalation performances were detected using powder X- ray diffraction (PXRD) and supported by Fourier Transform infrared spectroscopy (FTIR). The study for porosity of the composite was performed by BET analyzer. Among all of these concentrations, $0.5 \mathrm{M}$ represented the successful intercalation due to the presence of four sharp and intense harmonic peaks at $2 \theta$ with basal spacing of 24.6 $\AA, 12 \AA, 8 \AA$ and $6 \AA$, respectively. Herbicides release study was conducted in three salt solution, sodium chloride, sodium carbonate and sodium phosphate. Sustain release of MCPA was faster in sodium phosphate solution by $85 \%$. This controlled release study was determined by UV-Vis spectrometry.
\end{abstract}

Keywords: MCPA; ZLH; ion-exchange; hydrothermal; controlled release

\section{INTRODUCTION}

The large-scale application of herbicides and pesticides in agricultural activities increases the amount of chemical residual in soil, thus lead to serious environmental problem. This heavy usage of herbicides may cause huge loss due to volatilisation, photodegradation, leaching and surface migration (Wanyika, 2014). The unsustainable of economy and serious ecological pollution caused by herbicides required the solution for future advantages.

Layered hydroxide is an inorganic material that has a function as host to build the organic-inorganic nanocomposites. They constructed of layered structure and interact with cationic compound to develop the intercalation complex associate with basal spacing enlargement (Augusto et al., 2016).
These guest-host layered solid grouped into two, Layered Hydroxide Salt (LHS) and Layered Double Hydroxide (LDH). LHS are consist into two divisions, Hydroxide Double Salts (HDS) and Layered Metal Hydroxide (LMH). Zinc Layered Hydroxide (ZLH) is in group of LHS which zinc act as metal cation. In ZLH, inorganic layer represented by zinc and hydroxyl. The structure of ZLH consists of two parts which are brucite-like inorganic layer with positively charged and another part is interlayer where contain exchangeable anion and water. The general formula represented by $\mathrm{M}(\mathrm{II})(\mathrm{OH})_{2-\mathrm{x}}\left(\mathrm{A}^{-\mathrm{n}}\right)_{\mathrm{x} / \mathrm{n}} \cdot \mathrm{yH}_{2} \mathrm{O}$ where $\mathrm{M}(\mathrm{II})$ is a divalent cation $\left(\mathrm{Ca}^{2+}, \mathrm{Mg}^{2+}, \mathrm{Zn}^{2+} . \mathrm{Co}^{2+}, \mathrm{Ni}^{2+}, \mathrm{Cu}^{2+}, \mathrm{Mn}^{2+}\right)$ and $\mathrm{A}^{-\mathrm{n}}$ is an interlayer anion $\left(\mathrm{Cl}^{-}, \mathrm{NO}^{3}, \mathrm{ClO}^{4-}, \mathrm{CO}^{3-}, \mathrm{SO}_{4}{ }^{2-}\right.$, and many other inorganic anions) (Hussein et al., 2012). The reaction of host layer with interlayer anion take place by ionic bonding, hydrogen bonding and Van der Waals force (Duan et al., 2011). 
ZLH has great stability and potential as host for number of guest anions that come with different sizes due to its high charge density and large interspacing gallery. Consequently, researchers found its ability as delivery system in numerous application such as herbicides, catalyst, drugs and sunscreen absorber (Salleh et al., 2017).

This study aimed for development of ZLH host intercalated with 2-methyl-4-chlorophenoxyacetic Acid (MCPA). MCPA molecular structure as shown in Figure 1 is classified as chlorophenoxy herbicides that been widely used to control broadleaf weeds that against the growth of grain, paddy, corn and sugarcane (Inacio et al., 2001). The excessive use of this herbicide may cause water and soil pollution due to its toxicity. In addition, it is classify in Class III hazardous herbicides as slightly hazardous which may lead to skin irritation upon direct exposure (Hasanuddin et al., 2018).

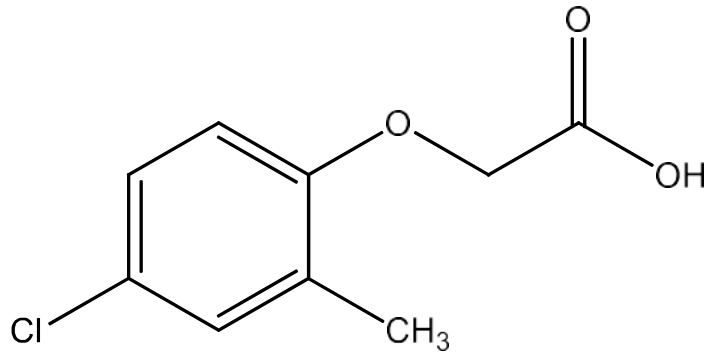

Figure 1. 2-methyl-4-chlorophenoxyacetic acid

Therefore, in order to downsize these problems, MCPA was chosen as one of suitable guest anion to intercalate with ZLH to formulate new herbicide delivery system that is more efficient compared to conventional one. Various concentration of MCPA ranging from $0.1 \mathrm{M}$ to $0.9 \mathrm{M}$ were synthesised and undergo hydrothermal treatment. The controlled release property of the most successful intercalation of ZMPCA was further determined

\section{MATERIALS AND METHOD}

\section{A. Synthesis of Materials}

All the chemicals used to synthesise the material are used directly without purification. The synthesis of ZMCPA was done by ion-exchange method followed by hydrothermal treatment. Absolute ethanol was prepared with deionised water in 9:1 ratio. In a $250 \mathrm{ml}$ conical flask, $0.2 \mathrm{~g} \mathrm{ZnO}$ was suspended into the prepared ethanol and stirred using magnetic stirrer for 15 minutes until completely dissolve (Ahmad et al., 2016). MCPA with concentrations 0.08 M, 0.1 $\mathrm{M}, 0.3 \mathrm{M}, 0.5 \mathrm{M}, 0.7 \mathrm{M}$ and $0.9 \mathrm{M}$ were diluted with $30 \mathrm{ml}$ ethanol to dissolve the solid materials. The MCPA solution was then added dropwise to $\mathrm{ZnO}$ suspension with constant stirring to allow the reaction to take place. The clear mixed solution was adjusted in range $\mathrm{pH} 7.0 \pm 7.5$ with slow addition of 2.o $\mathrm{M} \mathrm{NaOH}$ until white precipitate formed. The slurry solution was then stirred for 5 hours in room temperature before ageing in $70^{\circ} \mathrm{C}$ in oil bath shaker for 18 hours (Hussein et al., 2012). White precipitate was then undergoes hydrothermal treatment for $120^{\circ} \mathrm{C}$ in 2 hours before centrifuged at $180 \mathrm{rpm}$ within 10 minutes. The white precipitate washed with deionised water for at least three times and dried in oven at $60^{\circ} \mathrm{C}$ until the completely dry (Nabipour et al., 2015). The dry sample was kept in vial for further characterisation.

\section{B. Characterisation of Materials}

The characterisation was done by using Fourier Transform Infrared Spectroscopy (FTIR) Perkin Elmer (Perkin Elmer, Waltham, MA, USA) with range $4000-400 \mathrm{~cm}^{-1}$ for $\mathrm{KBr}$ and $4000-650 \mathrm{~cm}^{-1}$ for ATR to analyse the elements contain in the materials. $\mathrm{KBr}$-FTIR used for $\mathrm{ZnO}$ powder sample while materials constructed of $0.1 \mathrm{M}$ and $0.5 \mathrm{M}$ MCPA were done using ATR-FTIR. The confirmation of materials was done by Powder X-ray Diffraction (PXRD) between $2^{\circ}$ and $60^{\circ}$ with Rigaku model Ultima IV analytical powder diffractometer unit (Rigaku Corporation, Tokyo, Japan) using filtered $\mathrm{Cu}-\mathrm{Ka}$ radiation $(\lambda=1.540562 \AA)$ at $40 \mathrm{kV}$ and $20 \mathrm{~mA}$ at the rate of $2^{\circ} \mathrm{min}^{-1}$. The Bruneaur-Emmett-Teller (BET) surface area of solids was determined by BET analyzer (Micromeritic model 3FLEX 3500). Determination of optical and surface morphology was studied by Field Emission Scanning Electron Microscope (FESEM-EDX) with brand Jeol model JSM-7600F.

\section{Controlled Release Study}

The release of MCPA guest species from the interlayer space of $\mathrm{ZLH}$ was determined by using $0.03 \mathrm{M} \mathrm{NaCO} 3$ and $\mathrm{Na}_{3} \mathrm{PO}_{4}$ at $\lambda_{\max }=268 \mathrm{~nm}$ using $\mathrm{T} 80+\mathrm{UV} / \mathrm{Vis}$ Absorption 
Spectrophotometer. The fine powder of $3 \mathrm{mg}$ intercalated compound were placed in the $3.5 \mathrm{~mL}$ of salts solution in the quartz cuvette (Suhana et al., 2019). The samples were released separately for 360 minutes. For calculation purpose, $100 \%$ release of MCPA was done by placed the intercalated compound in $2 \mathrm{M}$ hydrochloric acid $(\mathrm{HCl})$ and analysed by UV-Vis Spectrometer at $\lambda_{\max }=268$ $\mathrm{nm}$. The percentage of MCPA released from all aqueous solutions were calculated using the equation below.

Percentage Release $=\frac{\text { Absorbance of anions at time }}{\text { Absorbance of } 100 \% \text { release at time }} \times 100$

\section{RESULT AND DISCUSSION}

\section{A. X-Ray Diffraction Analysis}

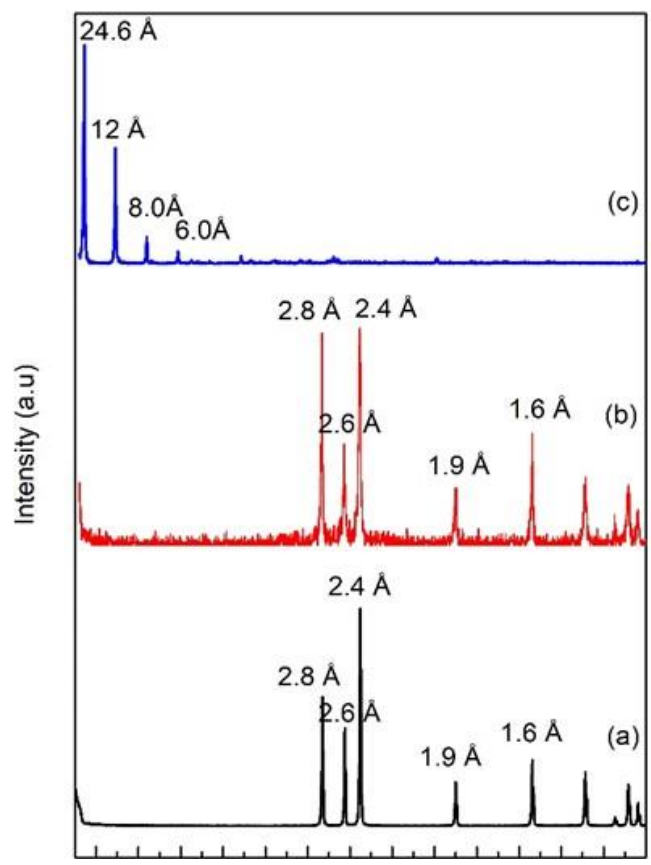

Figure 2. PXRD pattern for $\mathrm{ZnO}$ (a), o.1 M MCPA

(b) ando.5 M MCPA (c)

Figure 2(a) shows the PXRD pattern for pure $\mathrm{ZnO}$ with different peaks at between $2 \theta=30^{\circ}$ to $60^{\circ}$. The high intensity of each peaks with basal spacings $2.8 \AA$, $2.6 \AA, 2.4 \AA, 1.9 \AA$ and $1.6 \AA$, respectively, indicate the high crystallinity of $\mathrm{ZnO}$ (Salleh et al., 2017). Intercalation process of $\mathrm{ZnO}$ with MCPA were done with multiple different concentrations (0.1 M, 0.3 M, $0.5 \mathrm{M}, 0.7 \mathrm{M}$ and $0.9 \mathrm{M})$. At low concentration which is $0.1 \mathrm{M}$ MCPA ion, the PXRD pattern in Figure 2(b) shows the presence of pure $\mathrm{ZnO}$ peaks due to the appearance of $\mathrm{ZnO}$ in the composite. There are no new peaks observed except for some interference peaks. The MCPA concentration was increased to $0.5 \mathrm{M}$ as in Figure 2(c) and there are new peaks observed at lower degree of $2 \theta$. The formation of sharp and intense diffraction peaks at $2 \theta$ below than $10^{\circ}$ with basal spacings $24.6 \AA, 12 \AA, 8 \AA$ and 6 $\AA$ illustrated a pure phase material without any $\mathrm{ZnO}$ phase. This attribute that $\mathrm{ZnO}$ was perfectly converted to ZLH. In addition, there are no impurities peaks of MCPA detected, thus firmly support ZMCPA layered structure was well ordered and had very good crystallinity at this optimum concentration. The four harmonic peaks exhibit the successful intercalation of MCPA into interlayer region of ZLH (Hashim et al., 2019).

The intercalation of ZLH with its counter anion were known to follow dissociation-deposition mechanisms that consists of three steps (Hashim et. al., 2019; Megat et al., 2013). The first step referred to Equation (1) which $\mathrm{ZnO}$ undergoes hydrolysis with water. During the synthesis, $\mathrm{ZnO}$ was immersed in water that caused the surface hydroleses and form a layer of $\mathrm{Zn}(\mathrm{OH})_{2}$. This layer become more soluble in the presence of acid as in Equation (2). Therefore, the dissociation of $\mathrm{Zn}(\mathrm{OH})_{2}$ takes part to form $\mathrm{Zn}^{2+}+2 \mathrm{OH}^{-}$and caused the reaction in solution between $\mathrm{Zn}^{2+}$, hydroxyl, water and organic anions. This reaction cause generation of layered hydroxides compound as shown in Equation (3). This process will continuously occur and will stop once $\mathrm{ZnO}$ and $\mathrm{Zn}(\mathrm{OH})_{2}$ was perfectly converted to layered organicinorganic hybrid compound. Equation (4) indicated the overall process for intercalation of ZLH with the anions.

$$
\begin{aligned}
& \mathrm{ZnO}+\mathrm{H}_{2} \mathrm{O} \rightleftharpoons \mathrm{Zn}(\mathrm{OH})_{2} \\
& \mathrm{Zn}(\mathrm{OH})_{2} \rightleftharpoons \mathrm{Zn}^{2+}+2 \mathrm{OH}^{-} \\
& \mathrm{Zn}(\mathrm{OH})_{2} \rightleftharpoons \mathrm{Zn}^{2+}+2 \mathrm{OH}^{-} \\
& \mathrm{Zn} 2++2 \mathrm{OH}-+\mathrm{MCPA}-+\mathrm{H} 2 \mathrm{O} \rightleftharpoons \\
& \mathrm{Zn} 2+(\mathrm{OH})_{2}-\mathrm{x}(\mathrm{MCPA}-) \times . n \mathrm{H}_{2} \mathrm{O}
\end{aligned}
$$

In order to understand more about the intercalation formation, theoretical illustration of $3 \mathrm{D}$ molecular size of MCPA was proposed as illustrated in Figure 3 as estimated by Chem3D software version 12. The long and short axes and molecular thickness of MCPA were calculated 6.57 ̊, $12.54 \AA$ and $14.16 \AA$ respectively. 


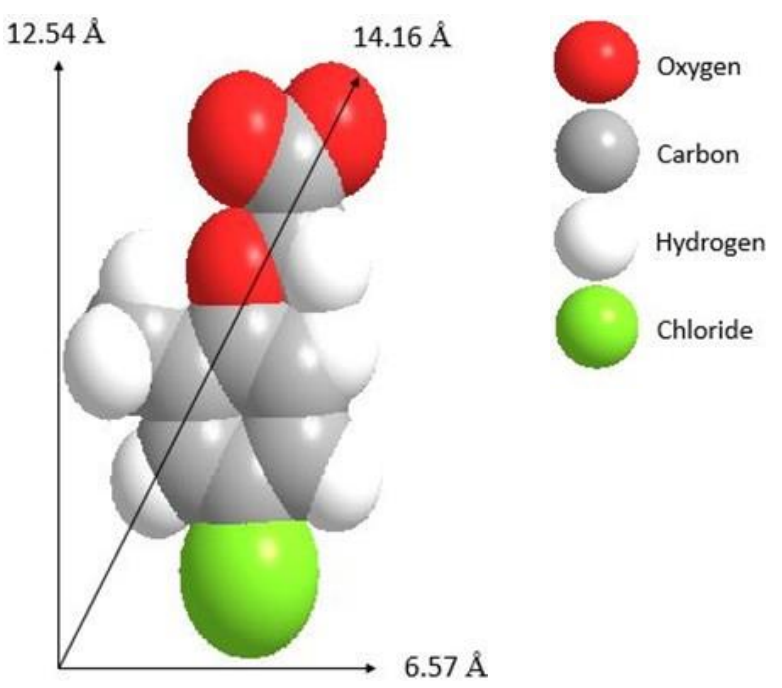

Figure 3. Three-dimensional molecular size of MCPA

The intercalation process results in expansion of basal spacing. This was studied from the theoretical illustration of MCPA as discussed. The basal spacing's increment was due to large size of anion molecules and the orientation of the molecules in the interlayer gallery of ZLH as shown in Figure 4 .

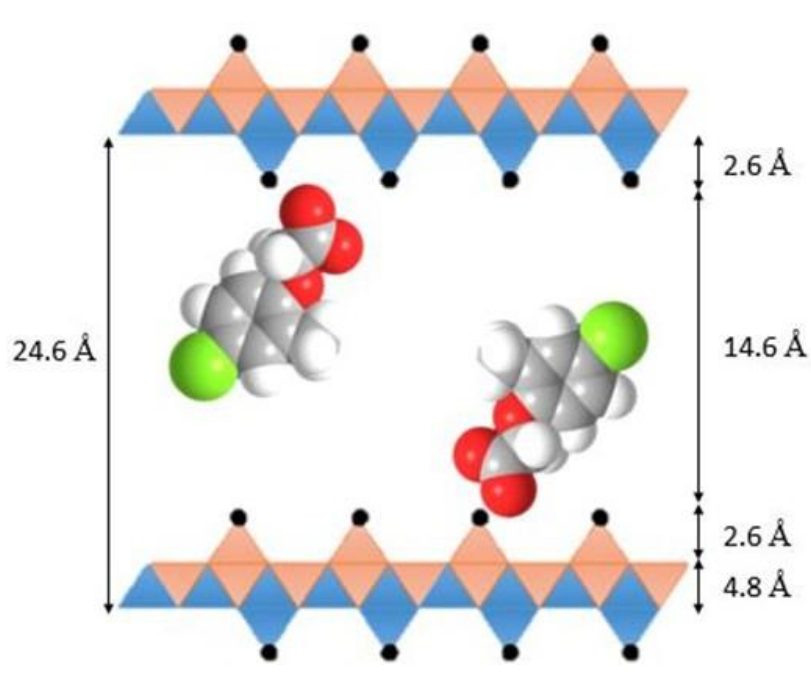

Figure 4. Illustration of spatial orientation MCPA between ZLH interlayer

The brucite-like inorganic layer have thickness $4.8 \AA$ and 2.6 ̊ for each zinc tetrahedron (Bashi et. al., 2013; Hashim et. al., 2019; Ramli et al., 2013). These values were subtracted with basal spacing value obtained from PXRD which is 24.6 A. Therefore, the interlayer gallery height was calculated to $14.6 \AA$. As can be refer to Figure 3, the longest axes of MCPA is $12.54 \AA$ which was smaller than interlayer gallery value. Therefore, it was proposed that MCPA was arranged in monolayer, where the carboxylate - $\mathrm{COO}$ - was attached through oxygen atom with zinc cation [22].The orientation of MCPA in the interlayer gallery of ZLH was tilting. As shown in the Figure 4, the attachment of carboxylate to the inorganic layer in order to balance the electrical charge. In concern of layer's charge density, anion dimension and by assuming anion keeps intact after interleaved, the MCPA needs to be oriented by place the functional group at opposite side and oppose the field of aromatic ring by $\pi-\pi$ interactions (Megat $e t$ al., 2013). Previous study done by [16] found that the interlayer spacing of ZLH is greater than LDH in order to allow the intercalation of anions with distinctive sizes, due to the higher charge density.

\section{B. FTIR Spectroscopy}

FTIR was used to support the intercalation result from PXRD. From ATR-FTIR and KBr-FTIR, the intercalation of MCPA was compared with pure $\mathrm{ZnO}$ and pure MCPA.

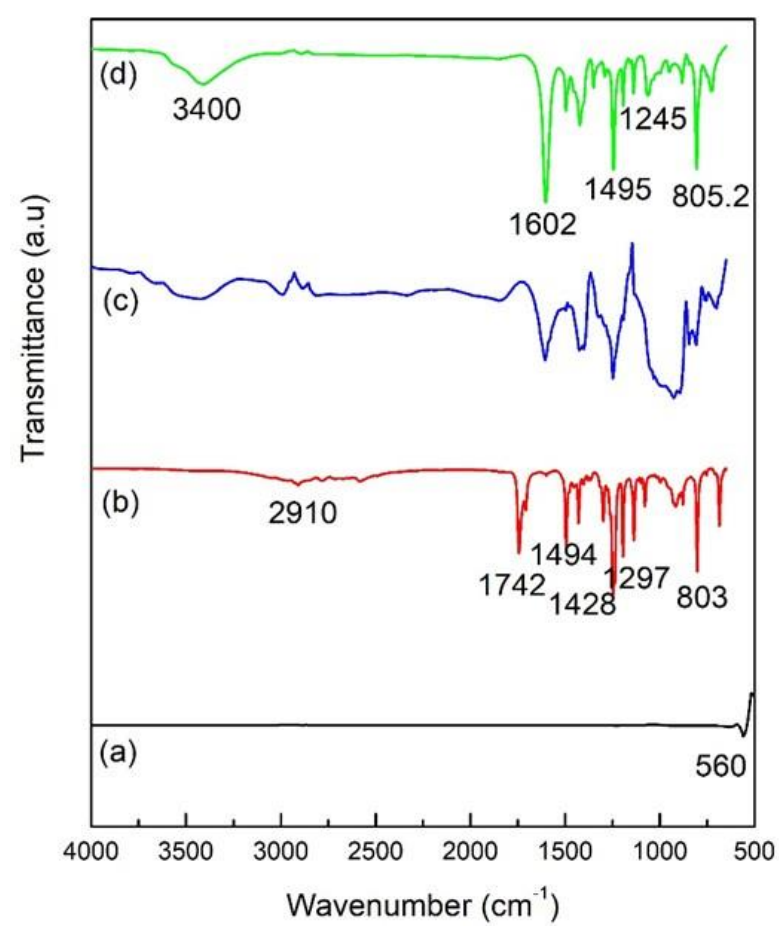

Figure 5. KBr-FTIR spectrum for (a) ZnO and (b) ATRFTIR spectrum for (b) pure MCPA, (c) 0.1 M MCPA, (d) 0.5 M MCPA

KBr-FTIR have $100 \%$ transmittance in the range of wave number 4000-400 $\mathrm{cm}^{-1}$ while ATR-FTIR have smaller transmission window which is $4000-600 \mathrm{~cm}^{-1}$. As shown in Figure 5(a), the $\mathrm{ZnO}$ peak appeared at $560 \mathrm{~cm}^{-1}$, which can detect by KBr-FTIR compared to ATR-FTIR. This single peak was observed at lower region due to vibration of zinc and 
oxygen sublattices (Ahmad et al., 2016). For the pure MCPA Figure 5(b), a broad band was detected at $2910 \mathrm{~cm}^{-1}$ indicated to $\mathrm{O}-\mathrm{H}$ stretching vibration of $\mathrm{COOH}$. A sharp and intense band was appeared at $1742 \mathrm{~cm}^{-1}$ attributed to $\mathrm{C}=\mathrm{O}$ stretching. Distinct band at $1494 \mathrm{~cm}^{-1} 1428 \mathrm{~cm}^{-1}$ were assembled the stretching vibration of $\mathrm{C}=\mathrm{C}$ of aromatic ring, an intense peak at $1297 \mathrm{~cm}^{-1}$ corresponding to symmetric and asymmetric stretching mode of $\mathrm{C}-\mathrm{O}-\mathrm{C}$ vibration. The peak observed at $803 \mathrm{~cm}^{-1}$ belongs to $\mathrm{C}-\mathrm{Cl}$ stretching vibration (Halimah et al., 2013). The intercalation of ZMCPA at 0.1 M Figure 5(c) showed broad band at $2984 \mathrm{~cm}^{-}$ ${ }^{1}$ which is $\mathrm{OH}$ stretch for carboxylic acid. There are also presence of bands at $1605 \mathrm{~cm}^{-1}, 1248 \mathrm{~cm}^{-1}$ and $804 \mathrm{~cm}^{-1}$ that belongs to $\mathrm{C}=\mathrm{C}$ aromatic, $\mathrm{C}-\mathrm{O}-\mathrm{C}$ stretch and $\mathrm{C}-\mathrm{Cl}$ functional group respectively. FTIR spectrum for $0.5 \mathrm{M}$ ZMCPA at Figure 5(d) showed a broad spectrum at 3400 $\mathrm{cm}^{-1}$ belongs to $\mathrm{O}-\mathrm{H}$ stretching vibration due to presence of water molecules that had been absorbed in the interlayer region. An intense peak at $1602 \mathrm{~cm}^{-1}$ signify the presence of $\mathrm{C}=\mathrm{C}$ vibration of aromatic ring. $\mathrm{COO}^{-}$is the most important feature in FTIR spectra for ZMCPA. Therefore, this functional group detected at $1495 \mathrm{~cm}^{-1}$ and prove there are stretching of $\mathrm{COO}^{-}$for ZMCPA hybrid, 1245 $\mathrm{cm}^{-1}$ assembled C-O-C stretch. A peak at $805.2 \mathrm{~cm}^{-1}$ correspond to $\mathrm{C}-\mathrm{Cl}$ stretching vibration of ZMCPA. By comparing ZMCPA with its pure $\mathrm{ZnO}$ and pure MCPA, the spectra are not confirmed if there are any appearance or disappearance of $\mathrm{ZnO}$ band at lower wavenumber. However, based on PXRD result, there are confirmation that that $\mathrm{ZnO}$ was completely react with $\mathrm{MCPA}$ in aqueous solution and became a new composite. Therefore, it suggested that MCPA anion was successfully intercalated into ZLH interlayer galleries (Salleh et al., 2017).

\section{Elemental Analysis}

The surface area and porosity of $\mathrm{ZnO}$ and new composite, ZMCPA was tabulated in Table 1 below by using nitrogen adsorption-desorption method.

From Table 1, the successful intercalation of 0.5 M MCPA with ZLH should increase the surface area. However, the result showed decreased the Brunauer-Emmett-Teller
(BET) surface area from $6.3688 \mathrm{~m}^{2} / \mathrm{g}$ to $5.1387 \mathrm{~m}^{2} / \mathrm{g}$. The decrement may be due to agglomeration of ZMCPA sample. The intensity of pore volume distribution shows a higher value for ZMCPA compared to zinc oxide, indicated modification of pore texture with a new intercalated compound in the interlayer zinc layered hydroxide of the former. Based on the PXRD diffractogram, the intercalation of lead to formation of pure phase material with higher basal spacing. Therefore, it resulted in increase of pore texture in crystallites with larger diameter significantly from $103.588 \AA$ to $288.787 \AA$ (Halimah et al., 2013). In order to understand more about surface properties of this composite, the adsorption-desorption isotherm and pore size distribution are discussed in Figure 6 by comparing $\mathrm{ZnO}$ with its new composite, ZMCPA.

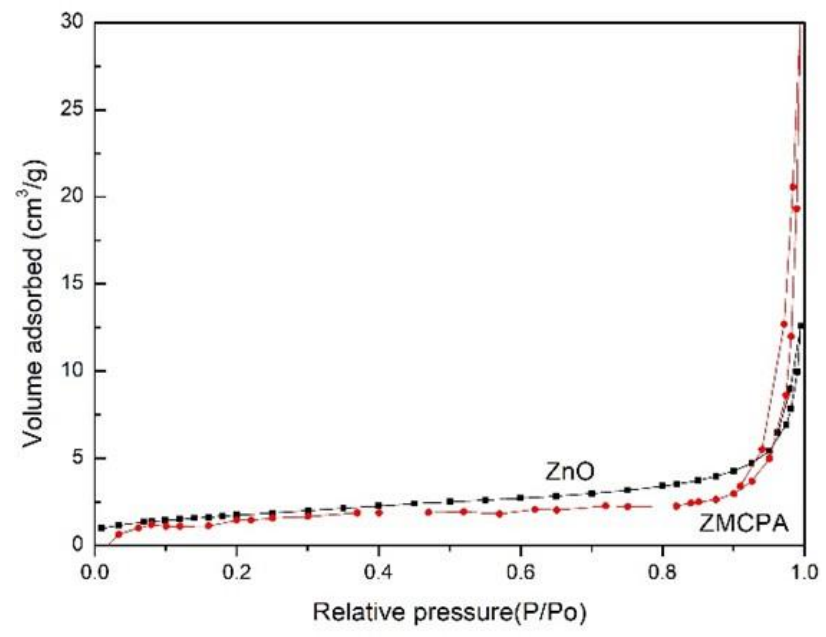

Figure 6(a). Nitrogen adsorption-desorption isotherm of $\mathrm{ZnO}$ and ZMCPA

Based on Figure 6(a) the nitrogen adsorption-desorption isotherm for ZMCPA described the characteristic as Type IV in IUPAC classification, illustrating a mesopore-type of material (Hashim et al., 2017). The slow increment of adsorption observed at lower relative pressure up to 0.8 , followed by rapid increment of adsorption at 0.8 and above the relative pressure. The adsorption branch of hysterisis loop for ZMCPA was slightly wider than $\mathrm{ZnO}$ that attribute as different pore texture for both of these materials. This is the consequence to the high basal spacing of ZLH after addition of MCPA during the intercalation process (Halimah et al., 2013). 
Table 1. Surface area and porosity of $\mathrm{ZnO}$ and $\mathrm{ZMCPA}$

\begin{tabular}{cccc}
\hline Sample & BET Surface Area $\left(\mathbf{m}^{2} / \mathbf{g}\right)$ & BJH Average Pore Diameter & BJH Pore Volume (cm $\mathbf{3} / \mathbf{g})$ \\
& & $(\AA)$ & 0.01525 \\
\hline $\mathrm{ZnO}$ & 6.3688 & 103.588 & 0.03233 \\
\hline
\end{tabular}

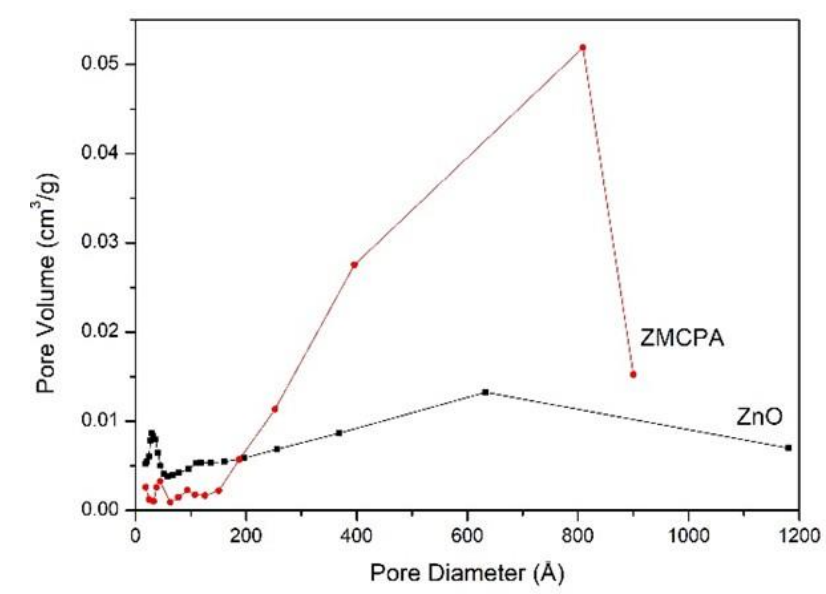

Figure 6(b). BJH Desorption Pore Size Distribution of ZnO and ZMCPA

Meanwhile, Figure 6(b) showed the BJH desorption pore size distribution for $\mathrm{ZnO}$ and its nanocomposite, $\mathrm{ZMCPA}$. The specific value of pore volume and pore diameter can be referred to Table 1. A sharp single-peaked pore distribution observed at centre of $809 \AA$ for ZMCPA. Besides, ZnO also showed a sharp peak at $632 \AA ̊$ however the pore size of $\mathrm{ZnO}$ is lower than ZMCPA by refer to Table 1 . This may be arise from the development of interstitial pores between the crystallite, different particle size, morphology and aggregation during the formation of the composite (Hasanuddin et al., 2018).

\section{Surface Morphology}

The scanning electron micrograph of $\mathrm{ZnO}$ and intercalated particle ZMCPA as shown in Figure 7. $\mathrm{ZnO}$ exhibits the surface morphologies of very fine particles and non-uniform shapes and sizes of granular structure [11]. The intercalation of MCPA into interlayer gallery of ZLH by direct method transformed $\mathrm{ZnO}$ particles to agglomerate of thin and platelike structure with different sizes. This proven that intercalation process between ZLH and MCPA has changed the surface morphology of small $\mathrm{ZnO}$ particles into sheet-like structure of ZMCPA [13].

Meanwhile, the energy dispersive X-Ray spectroscopy (EDX) analyse the elemental composition that had been exist in both particles (Haan et. al., 2018; Mah et al., 2016). As from Figure 7(b)(ii), element $\mathrm{C}, \mathrm{O}, \mathrm{Cl}$ and $\mathrm{Zn}$ are obtained from the spectrum with weight percentage $65.1 \%, 14.2 \%, 11.8 \%$ and $8.9 \%$, respectively. This can be distinguished by Figure 7 (a)(ii) that mainly composed by $\mathrm{Zn}$ and $\mathrm{O}$ with weight percentage $79.8 \%$ and $20.2 \%$, respectively. The comparison between both EDX spectrum suggested that intercalation of MCPA in the interlayer gallery of ZLH occur and incorporate to produce ZMCPA.

\section{E. Controlled Release Study}

The release of MCPA from three different aqueous solutions were studied and discussed based on the release profile as shown in Figure 8.

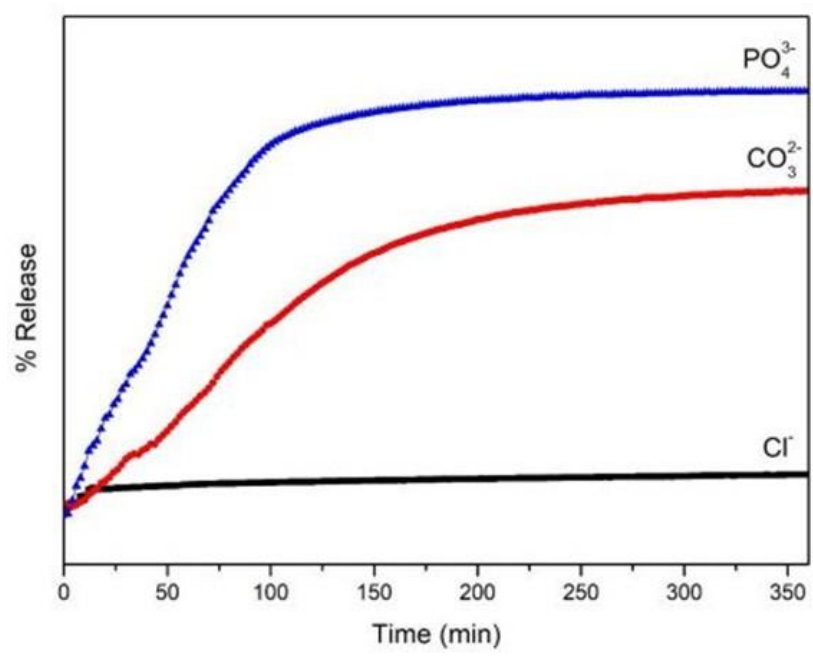

Figure 8. Controlled release of MCPA anion at $0.03 \mathrm{M} \mathrm{NaCl}$, $\mathrm{Na}_{2} \mathrm{CO}_{3}$ and $\mathrm{Na}_{3} \mathrm{PO}_{4}$ 
Three media aqueous solutions with concentration at $0.03 \mathrm{M}$ were used for release studies which including sodium phosphate, sodium carbonate and sodium chloride. The release media was considered based on the components of soil and rainwater (Hashin et al., 2014). The charge density of each media are described in Table 2. This controlled release studies were performed in 360 minutes.
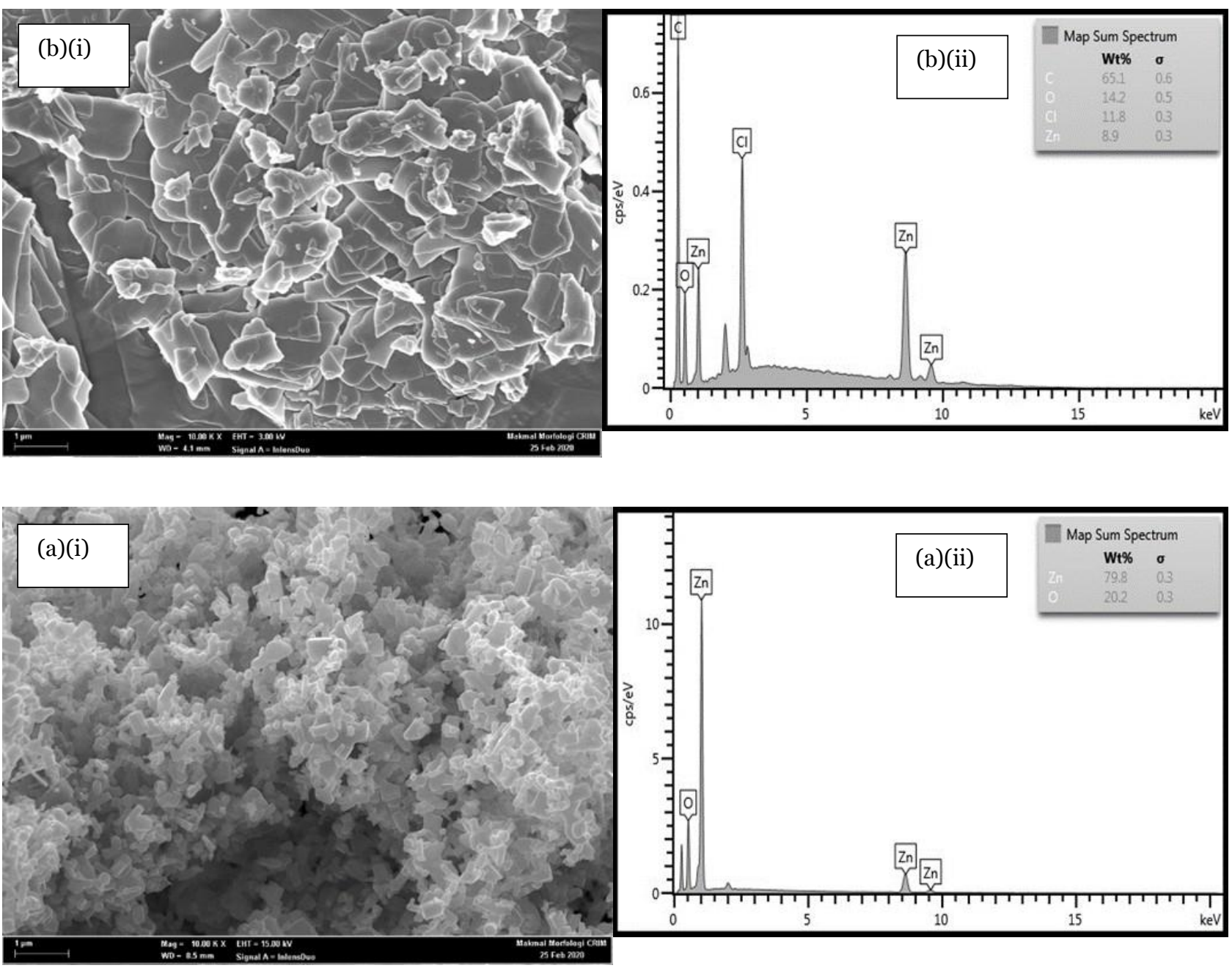

Figure 7. Surface morphology of ZnO (a)(i) and ZMCPA (b)(i) by FESEM experimental composition of $\mathrm{ZnO}$ (a)(ii) , ZMCPA and (b)(ii) by EDX 
Table 2. Anions and charge density of aqueous media solution

\begin{tabular}{ccc}
\hline Media solution & Anion & Charge density \\
\hline $\mathrm{NaCl}$ & $\mathrm{Cl}^{-}$ & -1 \\
$\mathrm{Na}_{2} \mathrm{CO}_{3}$ & $\mathrm{CO}_{3}{ }^{-2}$ & -2 \\
$\mathrm{Na}_{3} \mathrm{PO}_{4}$ & $\mathrm{PO}_{4}^{-3}$ & -3 \\
\hline
\end{tabular}

As shown in the release profile, rapid release was observed in all solutions at beginning of time and followed by more sustained release. The accumulated release percentage of MCPA was highest for $\mathrm{Na}_{3} \mathrm{PO}_{4}$ followed by $\mathrm{Na}_{2} \mathrm{CO}_{3}$ and $\mathrm{NaCl}$ by $85 \%, 65 \%$ and $8 \%$, respectively. This observation due to different charge density values. The anions act as sacrificial anions that drive the release of MCPA from interlayer gallery of ZLH (Hashim et al., 2014). Sodium phosphate have highest anion affinity to undergo ion exchange with MCPA whereby sodium chloride has lowest affinity. The sequence of affinity are as follows, $\mathrm{PO}_{4}{ }^{3-}>\mathrm{CO}_{3}{ }^{2-}>\mathrm{Cl}^{-}$.

At $\mathrm{Na}_{3} \mathrm{PO}_{4}$ solution, more ion exchange and faster release occur which sustain release occur after 80 minutes. Fast release of MCPA from its composite due to higher charge density of phosphate. This led to high electrostatic interaction occur between the phosphate anion with positive charge of zinc layered hydroxide (Hashim et al., 2014). High amount of counter anion release was also due to weaker electrostatic interaction between ZLH host with its anion species (Bashi et al., 2013).

The release of MCPA under $\mathrm{CO}_{3}{ }^{2-}$ influence exhibited with initial "burst effect" due to outer surface of layered ZLH was not able to absorb the large amount of MCPA released (Ahmad et al., 2015). Equilibrium state reached started from minutes of 160 that indicate the herbicide undergo slow release at this stage.

Based on the diffractogram in Figure 2, the intense peaks appeared which indicate high crystallinity of the composite.

Therefore, some findings in controlled release proposed that high crystallinity of composite usually chosen as release study due to its larger size, as the anion will release slower compared to the lower crystallinity and smaller molecule size. The particle sizes affect the stability of guest arrangement and limited surface area for composite material to undergo ion exchange process with the anions (Hashim et al., 2014).

\section{CONCLUSION}

In this study, the composite was synthesised by ion-exchange reaction with hydrothermal treatment method in which high temperature and high pressure applied to enhance the intercalation. The synthesis between zinc layered hydroxide and anion, MCPA herbicide was managed to form a new organic-inorganic composite known as ZMCPA. An ionexchange reaction with hydrothermal treatment method with different concentrations were used starting from $0.1 \mathrm{M}$ to $0.9 \mathrm{M}$ at constant $\mathrm{pH} 7 \pm 7.5$. PXRD results showed that the number of basal spacing of ZMCPA was 24.6 $\AA$. The peaks were sharp and intense indicate the high crystallinity. Formation of four harmonic peaks and disappearance of $\mathrm{ZnO}$ peaks attribute to succesful intercalation and $\mathrm{ZnO}$ was completely convert to ZLH. The successful intercalation occured as formation of pure phase material with basal spacing $24.6 \AA$ due to the presence of anion MCPA that occupied the interlayer gallery of ZLH. The results were further supported with ATR FTIR where oxide peak not observed in lower wavenumber region and sharp MCPA peaks observed. The release study conducted and MCPA herbicides showed high percentage release of MCPA from $\mathrm{Na}_{3} \mathrm{PO}_{4}$ solution by $85 \%$ for 360 minutes. Based on BET result, the surface area was decreased due to the agglomeration of ZMCPA. However, high basal spacing resulted in increase of $\mathrm{BJH}$ pore diameter from $103.588 \AA$ to $288.787 \AA$ as well as increasing of pore volume to $0.03233 \mathrm{~cm}^{3} / \mathrm{g}$. This study suggested the possibility of ZLH as carrier host for MCPA. However, more testing required for material improvement before it can be applied in agricultural field.

\section{ACKNOWLEDGEMENT}

The author would like to express gratitude to Universiti Teknologi MARA for the financial support through internal funding and facilities as well as many people in providing support to complete this project. 


\section{REFERENCES}

Ahmad, R, Hussein, MZ, Rasidah, W, Abdul, W, Sarijo, SH \& Hin, Y 2015, 'Evaluation of controlled- release property and phytotoxicity effect of insect pheromone zinc-layered hydroxide nanohybrid intercalated with hexenoic acid', Journal of Agricultural and Food Chemistry, vol. 63, pp. 10893-10902.

Ahmad, R, Hussein, MZ, Sarijo, SH, Wan Abdul Kadir, WR \& Yun Hin, TY 2016, 'Synthesis and characteristics of valeric acid-zinc layered hydroxide intercalation material for insect pheromone controlled release formulation', Journal of Materials, 2016, pp. 1-9.

Augusto, D, Fontes, F, Andreza, M, Lyra, M De, Gonc, T, Arau, L, Jose, S, Jose, P, Alves-ju, S \& Jose, P 2016, 'CaAl-layered double hydroxide as a drug delivery system: effects on solubility and toxicity of the antiretroviral efavirenz', Journal of Inclusion Phenomena and Macrocyclic Chemistry, vol. 85, pp. 281-288.

Bashi, AM, Hussein, MZ, Zainal, Z \& Tichit, D 2013, 'Synthesis and controlled release properties of 2,4dichlorophenoxy acetate-zinc layered hydroxide nanohybrid', Journal of Solid State Chemistry, vol. 203, pp. 19-24.

Duan, X, Lu, J \& Evans, DG 2011, 'Assembly chemistry of anion-intercalated layered materials', in Modern Inorganic Synthetic Chemistry, Elsevier BV, pp. 375-404.

Haan, TY, Rosnan, N 'Adilah \& Mohammad, AW 2018, Synthesis and characterization of $\mathrm{ZnO}$-decorated go nanocomposite material with different $\mathrm{ZnO}$ loading through sol-gel method', Jurnal Kejuruteraan, vol. 30, no. 2, 249255

Halimah, S, Sheikh, S, Izaddin, A \& Mohd, S 2013., 'Synthesis of nanocomposite 2-methyl-4-chlorophenoxyacetic acid with layered double hydroxide: physicochemical characterization and controlled release properties', Journal of Nanoparticle Research, vol. 15, no. 3, pp. 2-9.

Hasanuddin, NI, Dzulkifli, NN \& Ghazali, SAIS M 2018, 'The effect of different concentration of 2-methyl-4chlorophenoxy acetate acid on graphite oxide intercalation nanohybrid', International Journal of Engineering \& Technology, vol. 7(January), pp. 89-92.

Hasanuddin, Norilyani Izzati, Dzulkifli, NN, Sarijo, SH \& Ghazali, SAISM 2018, 'Physicochemical characterization and controlled release formulation on intercalated 2methyl-4-chlorophenoxy acetic acid-graphite oxide (mcpago) nanocomposite', Indonesian Journal of Chemistry, pp. 1-8.
Hashim, N, Hussein, MZ, Isa, I, Kamari, A, Mohamed, A, Jaafar, AM \& Taha, H 2014, 'Synthesis and controlled release of cloprop herbicides from cloprop- layered double hydroxide and cloprop-zinc-layered hydroxide nanocomposites', Open Journal of Inorganic Chemistry, vol. 4, pp. 1-9.

Hashim, N, Muda, Z, Sharif, SNM, Isa, IM, Ali, NM, Ghazuli, MR \& Hussein, MZ 2016, 'Preparation of zinc layered hydroxidechloroacetate nanohybrid using direct reaction method', Materials Research Innovations, vol. 21, no. 6, pp. 396-400.

Hashim, N, Sharif, SNM, Hussein, MZ, Isa, IM, Kamari, A, Mohamed, A, Ali, NM, Bakar, SA \& Mamat, M 2017, 'Layered hydroxide anion exchanger and their applications related to pesticides: a brief review', Materials Research Innovations, vol. 21, no. 3, pp. 129-145.

Hashim, N, Sharif, SNM, Isa, IM, Hamid, SA, Hussein, MZ, Bakar, SA \& Mamat, M 2017, 'Controlled release formulation of an anti-depression drug based on a L-phenylalanate-zinc layered hydroxide intercalation compound', Journal of Physics and Chemistry of Solids, vol. 105(February), pp. 3544 .

Hashim, N, Sharif, SNM, Muda, Z, Md Isa, I, Ali, NM, Bakar, SA, Sidik, SM \& Hussein, MZ 2019, 'Preparation of zinc layered hydroxide-ferulate and coated zinc layered hydroxide-ferulate nanocomposites for controlled release of ferulic acid', Materials Research Innovations, vol. 23, no. 4, pp. 233-245.

Hussein, MZ, Rahman, NSSA, Sarijo, SH \& Zainal, Z 2012, 'Synthesis of a monophasic nanohybrid for a controlled release formulation of two active agents simultaneously', Applied Clay Science, vol. 58, pp.60-66.

Hussein, MZ, Shazlirah, N, Abdul, S \& Sarijo, SH 2012, 'Herbicide-intercalated zinc layered hydroxide nanohybrid for a dual-guest controlled release formulation', International Journal of Molecular Sciences, vol. 13, pp. 7328-7342.

Inacio, J, Forano, C \& Besse, JP 2001, 'Adsorption of MCPA pesticide by MgAl-layered double hydroxides', Applied Clay Science, vol. 18, pp. 255-264.

Mah, CF, Yam, FK. \& Hassan, Z 2016, 'Investigation and characterization of zno nanostructures synthesized by electrochemical deposition', Procedia Chemistry, vol. 19, pp. 83-90.

Megat, S, Mohsin, N, Hussein, MZ, Sarijo, SH, Fakurazi, S, Arulselvan, P \& Hin, TY 2013, 'Synthesis of (cinnamate-zinc layered hydroxide) intercalation compound for sunscreen application', Chemistry Central Journal, vol. 26, no. 7, pp. 112.

Nabipour, H, Hosaini Sadr, M \& Thomas, N 2015, 'Synthesis, 
characterisation and sustained release properties of layered zinc hydroxide intercalated with amoxicillin trihydrate', Journal of Experimental Nanoscience, vol. 10, no. 16, pp. 1269-1284.

Ramli, M, Hussein, MZ \& Yusoff, K 2013, 'Preparation and characterization of an anti-inflammatory agent based on a zinc-layered hydroxide-salicylate nanohybrid and its effect on viability of Vero-3 cells', International Journal of Nanomedicine, vol. 8, pp. 297-306.

Salleh, NM, Mohsin, SMN, Sarijo, SH \& Ghazali, SAISM 2017, 'Synthesis and physico- chemical properties of zinc layered hydroxide-4-chloro- 2-methylphenoxy acetic acid (ZMCPA) nanocomposite', IOP Conference Series: Materials Science and Engineering, vol. 204, no. 1, pp. 1-5.

Salleh, Norhafiza Mohd, Sarijo, SH \& Kalam, A 2017, 'Synthesis and physico-chemical properties of zinc layered hydroxide- 3-4-dichlorohenoxy acetic acid (ZLH34D) nanocomposite', Key Engineering Materials, vol. 744, pp. 441-445.

Suhana, N, Ali, M, Hasanuddin, NI, Azizan, NA \& Abdullah, A 2019, 'Development of herbicide delivery system based on magnesium aluminium-4-chlorophenoxyacetic acid (Mac) nanocomposite', vol. 1, no. 2, pp. 152-157.

Wanyika, H 2014, 'Controlled release of agrochemicals intercalated into montmorillonite interlayer space', The Scientific World Journal, pp. 1-10. 